\title{
Studies on storage stability of probiotic Shrikhand obtained from safflower (Carthamus tinctorius)-blended milk
}

\author{
VP Jadhav, Jayashri P Hiremath, SD Kalyankar and CD Khedkar
}

Received: 21 September 2018 / Accepted: 15 January 2019 / Published online: 18 April 2019

(C) Indian Dairy Association (India) 2019

\begin{abstract}
Shrikhand is a semi solid, sweetish-sour, whole milk product, prepared from lactic fermented curd. The curd (dahi) is partially strained through a muslin cloth to remove the whey to yield Chakka. Sugar, flavour, colour and dry fruits/condiments are mixed into Chakka to form a soft homogenous mass known as Shrikhand. It is a nutritionally dense fermented milk product. Its nutritional and therapeutic value can further be enhanced by incorporating filled milk, fruit pulp or probiotics. Safflower seed is rich in essential fatty acid (78\% linoleic acid). Safflower milk blended probiotic Shrikhand was developed by using safflower milk, lactic culture, probiotic culture, sugar, powdered safflower petals (colorant) and mango flavour. Among the various levels of safflower milk-cow milk (CM) blends, lactic cultures and probiotic cultures tried in preparation of probiotic dahi, the blends of 30:70 safflower milk-CM, scored the highest. Chakka prepared from optimized probiotic Dahi used for Shrikhand preparation using 40\% sugar, $0.1 \%$ colour and 500 ppm mango flavour was adjudged the best. Modified Shrikhand showed 12.47, 9.40, 40.70, 63.77 and $1.09 \%$ of fat, protein, carbohydrate, total solids and titratable acidity (\% LA), respectively. Storage studies at refrigeration temperature $\left(5 \pm 1^{\circ} \mathrm{C}\right)$ revealed that the product retained acceptability for a period of 21 days.
\end{abstract}

Keywords: Probiotics, Polyunsaturated Fatty Acids (PUFA), Shrikhand, Safflower Milk

\footnotetext{
V P Jadhav, Jayashri P Hiremath,

Department of Dairy Chemistry, Dairy Science College, Karnataka Veterinary, Animal \& Fisheries Sciences University, Hebbal, Bengaluru560024 India

SD Kalyankar

Department of Dairy Technology

College of Dairy Technology, Udgir Distt. Latur (Under MAFSU, Nagpur), Maharashtra, India

CD Khedkar ( $\square)$

Department of Dairy Microbiology and Biotechnology

College of Dairy Technology, Pusad-445204 Distt. Yavatmal (Under

MAFSU, Nagpur), Maharashtra, India

E-mail:cdkhedkar@gmail.com
}

\section{Introduction}

India has a very rich variety of fermented foods prepared from milk, cereals, pulses vegetables, fruits and fish. Milk and milk products like Dahi, buttermilk, Lassi, Shrikhand. The Shrikhand is a traditional indigenous fermented semi soft, sweetened whole milk product prepared using Chakka (strained Dahi). Dairy products are likely to remain important dietary components because of their nutritional value, flavor and texture. There will continue to be a demand for traditional, high quality dairy products, despite increasing competition from non-dairy based products. Trend of value-added and health promoting milk-based products is increasing swiftly. In view of this the present investigation was undertaken to evaluate suitability of incorporating safflower solids in the Shrikhand.

Safflower (Carthamus tinctorius L.) is an oilseed crop, a member of the family 'Compositae' or 'Asteraceae'. Safflower has been grown in India since time immemorial. It is mentioned as kusumba in ancient scriptures. It has been grown in India for the orangered dye (Carthamin) and yellow dye (Carthamidin) extracted from its brilliantly colored flowers and for its quality oil, rich in polyunsaturated fatty acids (PUFA) like linoleic acid (78\%). Flowers of the Safflower are known to have many medicinal properties for curing several chronic diseases and are widely used in Chinese herbal preparations (Li and Mundel,1996). The tender leaves and shoots of safflower are used as pot herb and salad. These are rich in vitamin A, iron, phosphorus, and calcium. Bundles of young plants are commonly sold as a green vegetable in markets in India and some neighboring countries (Nimbkar, 2002; Sarode et al. 2007). Safflower can be grazed or stored as hay or silage. Safflower forage is palatable, and its feed value and yields are similar to or better than those for oats or alfalfa.

\section{Materials and methods}

\section{Bacterial cultures}

The mixed lactic cultures and probiotic cultures (Lactobacillus acidophilus LA-5 and Bifidobacterium bifidum BB-12) were obtained from the Deptt. of Dairy Microbiology. Whole milk was procured from the Student Experimental Dairy Plant (SEDP), Dairy 
Science College, Karnataka Veterinary and Fishery Sciences University (KVAFSU), Hebbal, Bengaluru (India) and the safflower seeds and safflower flower petals of Sharda variety were brought from the Parbhani district of Maharashtra state. The colourless artificial mango flavour was procured from Down Foods and Flavours, Bengaluru.

\section{Determination of chemical composition of safflower milk}

The compositional parameters viz. moisture, protein, fat, crude fiber, total carbohydrate, minerals and total solids were determined as per the method (AOAC, 2000).

\section{Physico-chemical analysis of optimized probiotic dahi and Shrikhand}

The product was prepared as shown in the flow diagram (Fig. 1). The physico-chemical analysis viz., fat, titratable acidity, protein, moisture, total solids of safflower milk blended optimized probiotic $d a h i$ and Shrikhand were determined as per the method described earlier (Indian Standards, 1980; Indian Standards, 1981). However, the $\mathrm{pH}$ was monitored by a digital meter and synersis was determined by the method mentioned earlier (Gatson et al. 2007).

\section{Microbial studies of the Shrikhand}

Storage studies were conducted at refrigeration temperature $\left(5 \pm 1^{\circ} \mathrm{C}\right)$ and every week the respective sets of the products were tested for its probiotic counts. To enumerate Bifidobacterium counts anaerobic condition was maintained (Harrigan 1998), coliform, yeast and mold counts (Indian Standards, 1980). The initial and final microbial counts were estimated. Samples were diluted to $10^{3}$ for coliform, yeast and mold counts whereas $10^{6}$ for probiotic count. The media used for enumeration of various microbial counts (Probiotic counts:(a) L. acidophilus-MRS agar and (b) Bifidobacterium counts- Bifidus agar; Coliform countsMacConkey's agar and Yeast and Mould counts-Potato Dextrose Agar) were as per the recommendations made earlier (HiMedia, 1998). To enumerate the bifidobacterial counts in the product, the product was packed in polythene cups, which were stored under anaerobic condition during the storage studies.

\section{Statistical analysis}

Analysis of variance technique (F-test) was employed for the nutrients composition and sensory characteristics to test the significant difference $(\mathrm{P} \leq 0.05)$ between control and safflower milk incorporated probiotic Shrikhand in the study. One-way analysis of variance was used for the storage study by using a statistical R-software.

\section{Results and discussion}

Physico-chemical characteristics of safflower milk-CM blended probiotic Shrikhand
The results pertaining to impact of safflower milk blending with CM in the preparation of probiotic Shrikhand are presented in (Table 1). Probiotic Shrikhand prepared from the Dahi obtained from safflower-blended milk (PSSM) showed higher fat and lower protein content compared to the control and probiotic Shrikhand without safflower milk (PS). All the three samples of Shrikhand were found to contain same total sugar content where as the PSSM showed low titratable acidity compared to remaining two types of Shrikhand samples. The total solid content was found to be 62.92, 62.60 and 63.77, respectively for all the three samples. Results reveal that there was a significant difference $(\mathrm{P} \leq 0.05)$ in the total solid contents among all the three products.

\section{Effect of storage on various chemical attributes of the optimized} safflower milk blended probiotic Shrikhand

The experimental and the control Shrikhand samples were stored at refrigeration temperature at $\left(5 \pm 1^{\circ} \mathrm{C}\right)$ and analysed for the attributes viz; soluble nitrogen, FFA and titratable acidity, once in week still visual defects were noticed.

\section{Effect of storage on soluble nitrogen of optimized probiotic Shrikhand}

The proteolytic activity of the viable bacteria present in control and Shrikhand samples represents the soluble nitrogen content. Results pertaining to impact of storage on sensory attributes of optimized probiotic shrikhand are presented in Table 2. The initial (day first) soluble nitrogen content was $0.50,0.54$ and $0.96 \%$ for control, PSWSM and probiotic PSSM, respectively. The soluble nitrogen percentage increased during storage period. At the end of storage period i.e. $28^{\text {th }}$ day, control Shrikhand, PSWSM and PSSM showed soluble nitrogen content of 1.19, 1.25 and $1.36 \%$, respectively. The soluble nitrogen content was significantly different in three products throughout the storage period. The values of soluble nitrogen give a clear indication of proteolytic activity of viable bacteria in probiotic Shrikhand. As the storage period advanced, production of lactic acid increased, which can inhibit the proteolytic activity of viable bacteria (Yadav et al. 2007).

\section{Effect of storage on FFA content of optimized probiotic shrikhand}

The lipolytic activity of the viable bacteria present in control and optimized probiotic shrikhand samples represents the free fatty acid content ( $\%$ oleic acid). The effect of storage at refrigeration temperature $\left(5 \pm 1^{\circ} \mathrm{C}\right)$ on FFA content is depicted in Table 2 . The FFA percentage increased during storage period. The FFA content at day $21^{\text {st }}$ was $0.38,0.39$ and $0.49 \%$ for control, probiotic shrikhand without safflower milk and PSSM, respectively. At the end of storage period i.e. $28^{\text {th }}$ day, the control shrikhand, probiotic Shrikhand without safflower milk and PSSM showed FFA content of $0.42,0.42$ and $0.55 \%$ oleic acid, respectively. Statistical analysis of the data revealed that PSSM contained significantly 


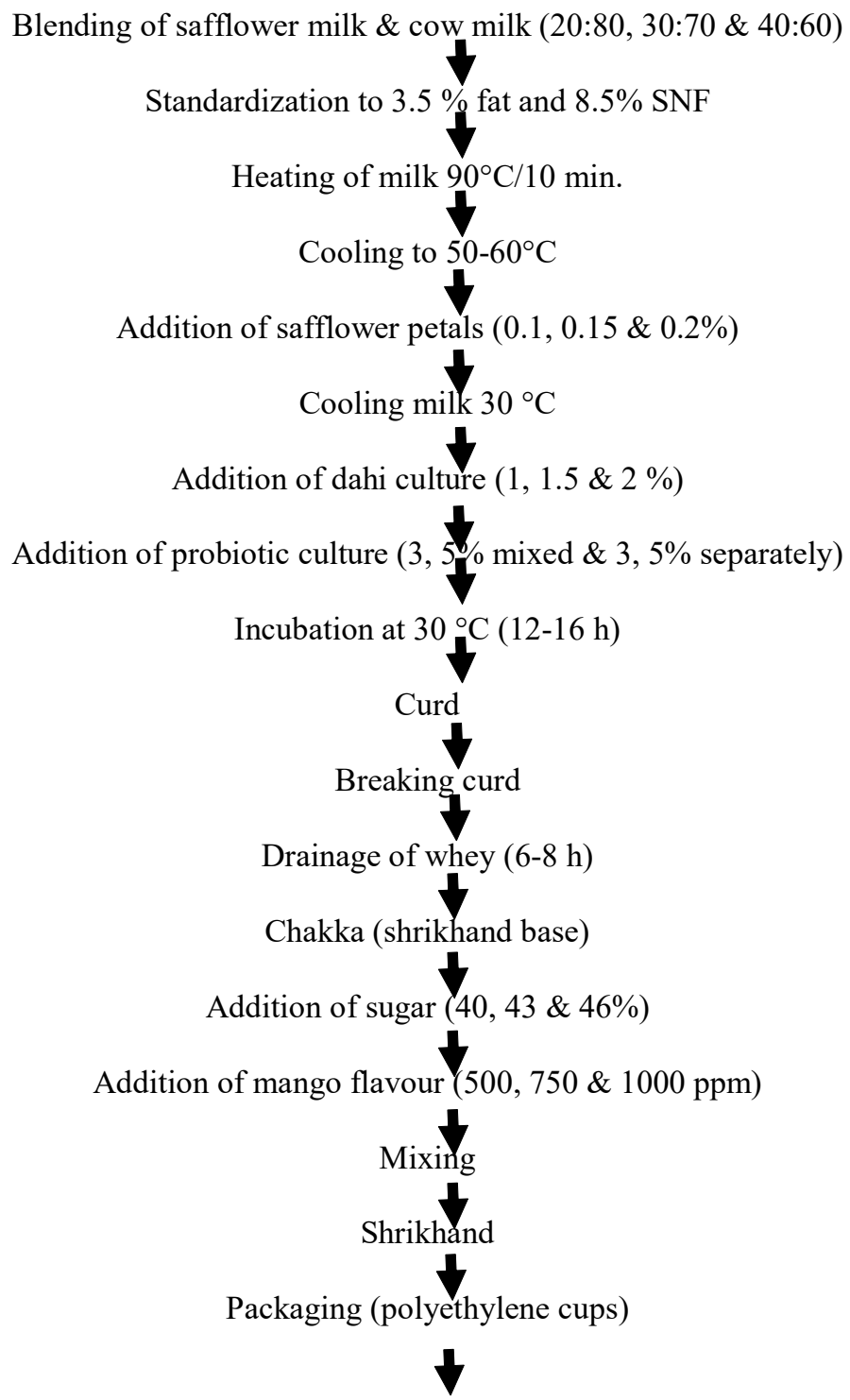

Storage at refrigeration temperature $\left(5 \pm 1^{\circ} \mathrm{C}\right)$

Fig. 1 Flow chart for production of Shrikhand

higher FFA content as compared with the control Shrikhand without safflower throughout the storage period.

\section{Effect of storage on titratable acidity of optimized probiotic shrikhand}

The effect of storage at refrigeration temperature $\left(5 \pm 1^{\circ} \mathrm{C}\right)$ on titratable acidity is shown in Table 2 . The titratable acidity at day first was found to be 1.19, 1.14 and 1.09 (\% LA) for control, PSWSM and PSSM, respectively. It was gradually increased during storage period. At the end of $28^{\text {th }}$ day, the control
Shrikhand, PSWSM and PSSM showed a titratable acidity of $1.44,1.41$ and 1.42 (\% LA), respectively. The rate of increase in acidity during the storage period in PSSM was slower as compared to the control and PSWSM. Statistical analysis revealed that the difference between the titratable acidities of PSSM and the control during the storage period was nonsignificant throughout the storage period.

Effect of storage on the microbial quality of the optimized probiotic shrikhand 
Table 1 Physicochemical characteristics of the optimized safflower milk blended probiotic Shrikhand

\begin{tabular}{|c|c|c|c|c|c|}
\hline Type of samp & Fat $(\%)$ & Protein $(\%)$ & Total sugar $(\%)$ & Titratable acidity $(\%$ LA) & TS $(\%)$ \\
\hline Control & $11.13^{\mathrm{a}}$ & $9.82^{\mathrm{a}}$ & $40.72^{\mathrm{a}}$ & $1.19^{\mathrm{a}}$ & $62.92^{\mathrm{a}}$ \\
\hline PS & $11.26^{\mathrm{a}}$ & $9.73^{\mathrm{a}}$ & $40.70^{\mathrm{a}}$ & $1.14^{\mathrm{a}}$ & $62.60^{\mathrm{b}}$ \\
\hline PSSM & $12.47^{\mathrm{b}}$ & $9.40^{\mathrm{a}}$ & $40.70^{\mathrm{a}}$ & $1.09^{\mathrm{a}}$ & $63.77^{\mathrm{c}}$ \\
\hline $\mathrm{CD}(\mathrm{P} \leq 0.05)$ & 0.30 & 1.41 & 0.08 & 1.74 & 0.20 \\
\hline
\end{tabular}

All the values are averages of three replications; Similar superscripts indicate non-significant differences at the corresponding critical differences.

Table 2 Effect of storage at $\left(5 \pm 1^{\circ} \mathrm{C}\right)$ on Soluble nitrogen (\%), Free fatty acid (\%oleic) content and Titratable acidity (\%LA) of the optimized probiotic Shrikhand

\begin{tabular}{lllllll}
\hline Type of sample & Parameters & \multicolumn{5}{c}{ Storage stability (days) } \\
\cline { 3 - 6 } & & 0 & 7 & 14 & 21 & 28 \\
\hline Control & Soluble nitrogen (\%) & $0.50^{\mathrm{a}}$ & $0.54^{\mathrm{a}}$ & $0.79^{\mathrm{a}}$ & $0.92^{\mathrm{a}}$ & $1.19^{\mathrm{a}}$ \\
& Free fatty acid (\% oleic) & $0.27^{\mathrm{a}}$ & $0.31^{\mathrm{a}}$ & $0.35^{\mathrm{a}}$ & $0.38^{\mathrm{a}}$ & $0.42^{\mathrm{a}}$ \\
& Titratable acidity (\% LA) & $1.19^{\mathrm{a}}$ & $1.25^{\mathrm{a}}$ & $1.31^{\mathrm{a}}$ & $1.38^{\mathrm{a}}$ & $1.44^{\mathrm{a}}$ \\
PSWSM & Soluble nitrogen (\%) & $0.53^{\mathrm{a}}$ & $0.58^{\mathrm{a}}$ & $0.81^{\mathrm{a}}$ & $1.00^{\mathrm{ab}}$ & $1.25^{\mathrm{ab}}$ \\
& Free fatty acid (\% oleic) & $0.27^{\mathrm{a}}$ & $0.32^{\mathrm{a}}$ & $0.36^{\mathrm{a}}$ & $0.39^{\mathrm{a}}$ & $0.42^{\mathrm{a}}$ \\
& Titratable acidity (\% LA) & $1.14^{\mathrm{b}}$ & $1.19^{\mathrm{a}}$ & $1.25^{\mathrm{b}}$ & $1.35^{\mathrm{b}}$ & $1.41^{\mathrm{b}}$ \\
PSSM & Soluble nitrogen (\%) & $0.96^{\mathrm{b}}$ & $1.13^{\mathrm{b}}$ & $1.24^{\mathrm{b}}$ & $1.26^{\mathrm{b}}$ & $1.36^{\mathrm{b}}$ \\
& Free fatty acid (\% oleic) & $0.31^{\mathrm{b}}$ & $0.37^{\mathrm{b}}$ & $0.42^{\mathrm{b}}$ & $0.49^{\mathrm{b}}$ & $0.55^{\mathrm{b}}$ \\
& Titratable acidity (\% LA) & $1.09^{\mathrm{c}}$ & $1.11^{\mathrm{b}}$ & $1.27^{\mathrm{b}}$ & $1.37^{\mathrm{c}}$ & $1.42^{\mathrm{b}}$ \\
& Soluble nitrogen (\%) & 0.43 & 0.32 & 0.34 & 0.30 & 0.15 \\
& Free fatty acid (\% oleic) & 0.01 & 0.03 & 0.04 & 0.08 & 0.11 \\
& Titratable acidity (\% LA) & 0.05 & 0.13 & 0.03 & 0.02 & 0.02 \\
\hline
\end{tabular}

All the values are averages of three replications; Similar superscripts indicate non-significant differences at the corresponding critical differences.

Table 3 Effect of safflower milk on the growth of Bifidobacterium bifidum in Shrikhand during the storage $\left(5 \pm 1^{\circ} \mathrm{C}\right)$

\begin{tabular}{lll}
\hline Storage period (days) & PS & PSSM \\
\hline 0 & Viable counts $(\log \mathrm{cfu} / \mathrm{g})$ & 9.08 \\
7 & 8.99 & 9.07 \\
14 & 8.98 & 7.96 \\
21 & 7.79 & 7.80 \\
28 & 7.70 & 5.63 \\
\hline
\end{tabular}

For the safety of consumer, yeast and mold and coliform counts in experimental Shrikhand was estimated. The control, PSWSM and PSSM were subjected to microbial analysis. The data on the influence of storage on the microbial quality of samples expressed as $\log _{10} \mathrm{cfu} / \mathrm{g}$ during 0 to 28 days of storage at $\left(5 \pm 1^{\circ} \mathrm{C}\right)$ at an interval of 7 days revealed that the yeast and mold count was nil in all the samples up to $21^{\text {st }}$ day of storage. A non significant difference was recorded on $28^{\text {th }}$ day in the yeast and mould counts.

\section{Effect of storage on coliform counts of the optimized probiotic shrikhand}

The coliform count was nil in control Shrikhand, PSWSM and PSSM up to $21^{\text {st }}$ day of storage at $\left(5 \pm 1^{\circ} \mathrm{C}\right)$. The counts on $28^{\text {th }}$ day of storage in the control, PSWSM and PSSM showed coliform counts of $1.84,1.47$ and $2.25 \mathrm{cfu} / \mathrm{g}$, respectively. The PSSM showed highest coliform counts compared to other samples on $28^{\text {th }}$ day that made the product unfit for consumption. The experimental probiotic shrikhand met the coliform requirement of FSSAI (2006) standards i.e. max. 50/g up to the $21^{\text {st }}$ day of storage. Hence the PSSM stored at $5 \pm 1{ }^{\circ} \mathrm{C}$ is safe for consumption only up to 21 days. Similar results were noticed for control nonprobiotic Shrikhand stored for 24 days and carrot enriched probiotic Shrikhand stored for 30 days at refrigeration condition prepared by using probiotic culture (Patil, 2014; Srinivasa, 2008).

Effect of safflower milk on the viability of Bif. bifidum in PSSM during the storage $\left(5 \pm 1^{\circ} \mathrm{C}\right)$ 
The effect of storage on the growth of Bif. bifidum in PSWSM and PSSM during storage period from 0 to 28 days at $\left(5 \pm 1^{\circ} \mathrm{C}\right)$ at an interval of 7 days is presented in Table 3 .

The counts on day $0,7,14,21$ and 28 were $8.99,8.98,7.79,7.70$ and 5.51, respectively for PSWSM whereas in PSSM the counts were 9.08, 9.07, 7.96, 7.80 and 5.63, respectively. As the storage period advanced, the viable counts decreased. It was observed that safflower milk exhibited slightly positive effect on the growth of Bif. bifidum counts. During the storage the counts decreased gradually in both types of Shrikhand. However, the PSSM retained the higher count of Bif. bifidum compared to the PSWSM. The counts showed declines during storage from 0 to 28 days in both types of Shrikhand. Earlier workers (Dave and Shah, 1998) reported a significant increase in the acidity of probiotic yoghurt in experimental samples as the storage period advanced.

The results obtained in the present investigation are comparable to those reported earlier (Krishana et al. 2011) where Lassi with added probiotic bacteria stored at $4 \pm 1^{\circ} \mathrm{C}$ for a period of 15 days showed 2 log cycle reduction of viable counts of $L$. acidophilus and Bif. bifidum at the end of the storage period. Acid production of lactic acid bacteria after the incubation decreased the viability of probiotic bacteria especially Bifidobacterium ssp (Ishibashi and Shimamura, 1993).

Reduction in viability of probiotic cultures (L. acidophillus and B. bifidum) in WPC enriched shrikhand stored at room temperature was reported earlier (Harrigan, 1998). However, in the present study, the viable counts of Bif. bifidum at $21^{\text {st }}$ days of storage at $5 \pm 1^{\circ} \mathrm{C}$, observed in experimental shrikhand was $\log 7.80 \mathrm{cfu} / \mathrm{g}$, minimum of $10^{6}$ cells of probiotics are required in a product to extend health benefits as many authors have suggested. The safflower milk incorporation in the preparation of probiotic Shrikhand might have supported the growth of Bif. bifidum proving its prebiotic effect.

\section{Conclusions}

It is concluded from the present investigation that formulated PSSM is nutritionally dense, which can be promoted for regular consumption. Synergy of dairy and agro products can bring down overall cost of production which can impart more benefits to the farmers as well as the lower. Formulated probiotic shrikhand has 21 days shelf-life at refrigeration temperature $\left(5 \pm 1^{\circ} \mathrm{C}\right)$ which can be improved by using advanced packaging techniques.

\section{References}

AOAC (2000) Official Methods of Analysis. Edited by Horwits W. Association of Analytical Chemists, Washington

Dave RI, Shah RK (1998) Ingredient supplementation, effect on viability of probiotics bacteria in yoghurt. J Dairy Sci 81:2804 - 2816

Gatson A, Goncalvez D, Perez C, Reolon G, Segura N, Leema P, Gambaro A (2007) Influence of gelatin and starch in the instrumental and sensory texture of stirred yoghurt. Intl J Dairy Technol 60(4):263269

Harrigan P (1998) Laboratory methods in food and dairy microbiology. Department of Science, Reading University. Academic Press Inc. (London) Ltd. U.K.

HiMedia Manual for Microbiology Laboratory Practice (1998) HiMedia Laboratory Pvt. Ltd, Ahemadabad

IS 9532 (1980) Chakka and Shrikhand (FAD 19: Dairy Products and Equipment's)

IS:Part II (1981) ISI hand book on food analysis, part XI- dairy products. Indian Standards Institution, New Delhi

Ishibashi N, Shimamura S (1993) Bifidobacteria: Research and development in Japan. J Food Technol 47: 126-136

Krishana M, Venkateshaiah BV, Prabha R (2011) Effect of prebiotics on probiotic Lassi. Indian J Dairy Biosci 22: 36-41

Li D, Mundel HH (1996) Safflower. Carthamus tinctorius L. promoting the conservation and use of underutilized and neglected Crops. Institute of Plant Genetics and Crop Plant Research, Gatersleben/ International Plant Genetic Resources Institute, Rome, $p p 83$

Nimbkar N (2002) Safflower rediscovered. Times Agri J 2: 32-36

Patil M (2014) Optimization of carrot enriched probiotic shrikhand. M.Tech. thesis submitted to KVAFSU, Bidar

Sarode AR, Khedkar CD, Kalyankar SD, Patil MR, Bajad DN, Sarode TR, Chavan SJ (2007) Studies on microbiological quality of Karadkheer: A value-added dairy product of Maharashtra. J Dairying, Foods and Home Sci 26(2):98-101

Srinivasa H (2008) Studies on the development of enriched probiotic shrikhand. M. Tech thesis submitted to KVAFSU, Bidar

Yadav H, Jain S, Sinha PR (2007) Evaluation of changes during storage of probiotic dahi stored at $7^{\circ} \mathrm{C}$. Intl J Dairy Technol 60(3): 205-210 